- The completion of a short dental anxiety questionnaire by adult patients immediately before seeing their general dental practitioner does not raise anxiety.

- Contrary to some expectations the answering of questions about dental anxiety does not have a deleterious effect on patients.

- Dentists are recommended to use dental anxiety questionnaires routinely as part of their general assessment of patients.

\title{
Does completing a dental anxiety questionnaire increase anxiety? A randomised controlled trial with adults in general dental practice
}

\author{
G. M. Humphris, ${ }^{1}$ H. M. M. Clarke ${ }^{2}$ and R. Freeman ${ }^{3}$
}

The assessment of dental anxiety can be achieved by using brief multiitem scales.

Objective To test the null hypothesis that completing the Modified Dental Anxiety Scale had no immediate influence on patient state anxiety.

Outcome measure Speilberger State Anxiety Inventory-6 item Short Form.

Study design Randomised controlled trial.

Participants Patients $(n=1,028)$ attending 18 dental practices in Northern Ireland were invited to participate.

Results Twenty-four patients refused (response rate 98\%) providing 1,004 patients (mean age $=41$ years, range $=16$ to 90 years; $65 \%$ female) for analysis. Patients who completed the dental anxiety scale were found to have a virtually identical state anxiety score: mean (SD) $=11.36$ (4.33) compared to those who completed the state anxiety assessment only: mean (SD) $=11.01$ (4.35). The mean (Cl95\%) difference was 0.35 (0.89 to -0.18$), t=1.29, d f 1002, p=0.2$.

Conclusion The completion of a brief dental anxiety questionnaire before seeing the dentist has a non significant effect on state anxiety.

\section{INTRODUCTION}

The assessment of dental anxiety is important for two reasons: first, to assist the dentist in the management of anxious patients and secondly to provide evidence-based research into this psychological construct which has been shown to predict dental avoidance. ${ }^{1}$ Various dental anxiety measures have been developed. ${ }^{2,3}$ Previous work by Kent has shown that the completion of a dental anxiety scale immediately prior to dental treatment does not influence the patient's pain experience. ${ }^{4}$ Replication

\footnotetext{
${ }^{1 *}$ Professor, Bute Medical School, University of St Andrews, Fife KY16 9TS; ${ }^{2}$ Southern Health and Social Services Board, Armagh BT61 9DR; ${ }^{3}$ Professor, Queen's University, Belfast, Dept of Paediatric, Preventive and Public Health Dentistry, School of Dentistry, RGH, Grosvenor Road, Belfast, BT12 6BP

${ }^{*}$ Correspondence to: Professor Gerry Humphris

Email:gerry.humphris@st-andrews.ac.uk
}

\section{Refereed paper}

Accepted 28 June 2005

DOI: $10.1038 /$ sj.bdj.4813772

๑ British Dental Journal 2006; 201: 33-35 of this study with eight to 14-year-old children supported this finding. ${ }^{5}$ The effect of completing these questions appeared to be beneficial in reducing self-reported pain experience. The authors argued that the encouragement of children to consider how anxious they were about certain dental procedures and the prospect of discomfort enabled them to prepare psychologically for their dental treatment. ${ }^{5}$ A recent survey of dentists with a special interest in dental anxiety found that the routine use of formal questionnaires to assess dental anxiety was very limited. ${ }^{6}$ This was disappointing when it was considered that dentists tended not to recognise dentally anxious patients from their observations and contact with patients in their surgeries. Reasons for the poor frequency of utilisation of questionnaires include lack of time and expertise in their interpretation. It was for this reason that the brief instrument: the Modified Dental Anxiety Scale (MDAS) was advocated. The brief nature and ease of interpretation lent itself to use within general practice. Anecdotal reports with dental practitioners has suggested another reason; that is, that some dentists believe that asking patients about their dental anxiety just before treatment would exacerbate anxiety. Hence the aim of the study was to test the hypothesis that the completion of a dental anxiety scale prior to treatment would raise situational anxiety (also known as state anxiety) in a general practice patient population.

\section{METHODS}

\section{Design of study}

A randomised controlled trial used a convenience cluster sampling of dental practices within a prescribed region of Northern Ireland. A power analysis found that a sample size of approximately 430 patients in each group would have $90 \%$ power to detect a small effect of a difference in mean of 1 (the difference between a Group 1 mean of 11 and a Group 2 mean of 12) assuming that the common standard deviation is 4.5 using a two group t-test with a 0.05 two-sided significance level. Patients were randomised by whole sessions (to avoid 'contamination') so that all attendees in a single session (defined as the typical period when the practice was open for a series of patients) were allocated to either the MDAS or no MDAS condition. The 
researcher on arrival at the practice for the start of the session opened an opaque sealed envelope in consecutive order from the stack of envelopes prepared previously through computer generated assignment for the study. Each envelope contained a slip inside indicating if the MDAS questionnaire was or was not to be employed in that session.

\section{Sample}

Eighteen practices were selected (32\% of all general dental practitioners) within the Southern Health and Social Services Board (SHSSB) in Northern Ireland. The mean Noble deprivation index, based upon the postcode of the practice, was 19.9 for participating dentists which compares closely to the average (20.14) for the SHSSB area. ${ }^{7}$ Approximately 50 eligible patients were consecutively drawn from each practice within a maximum of eight sessions per practice. Entry criteria included: aged 16 years or above, gave written consent and English language spoken. Visitors to the practice or relatives of patients were excluded. All refusals were noted.

\section{Measures}

The Modified Dental Anxiety Scale (MDAS) consists of five questions, which assess dental anxiety, and consists of inviting the respondent to report their dental anxiety prior to a dental visit, while sitting in the waiting room, waiting to have teeth drilled, waiting for scaling and waiting for local anaesthetic. This measure is similar to Corah's Dental Anxiety Scale, ${ }^{8}$ but includes an extra question about a local anaesthetic injection, as well as a simplified and consistent answering scheme across all questions. There are five responses to each question which range from 'not anxious' (scoring 1) to 'extremely anxious' (scoring 5). This gives a possible range of scores from 5 to 25 with scores of 19 and above as indicative of dental phobia. Reliability for this measure was also favourable (internal consistency $=0.89$; test-retest $=0.82$ ). ${ }^{9,10}$

A short version of Speilberger's State Trait Anxiety Inventory (STAI-S) was used. ${ }^{11}$ The STAI-S is a self-report measure designed to assess patient state anxiety at the time of completion. It is comprised of six statements depicting how the individual may feel, for example, 'I am calm'. The respondent chooses an answer from four response categories ranging from 'not at all' to 'very much'. Scores are summed (with some reverse scoring of individual items) to give a range from six (not at all anxious) to 24 (very anxious). The internal consistency for the six item scale is $0.82 .{ }^{12}$ The testretest for a state anxiety measure tends not to be calculated as it is typically low, however for the full form of the measure where it has been quoted (seven articles) has been found to be reasonable $($ mean $=0.70) .{ }^{13}$

\section{Procedure}

Consecutive participants during study sessions were invited to enter the study at the general dental practices on days where non-specialist, that is routine service, was provided. Patients in the MDAS condition completed the dental anxiety questionnaire followed by the STAIS-S, whereas those in the non MDAS arm of the study were invited to complete the STAIS-S only. Data were collected from July to August 2004 by two trained interviewers. Their role was to consent patients and hand the questionnaire to the respondent. To eliminate interviewer bias the patients were not guided through the questionnaire. Research protocol had been authorised by the Local Research Ethics Committee.

\section{Statistical analysis}

Data were analysed by SPSS for Windows $\mathrm{v} 12^{\mathrm{TM}}$. Frequencies and means were calculated on variables where appropriate. Confidence intervals were calculated. ${ }^{14}$ Cross-tabulations of categorical variables were inspected to test for biased

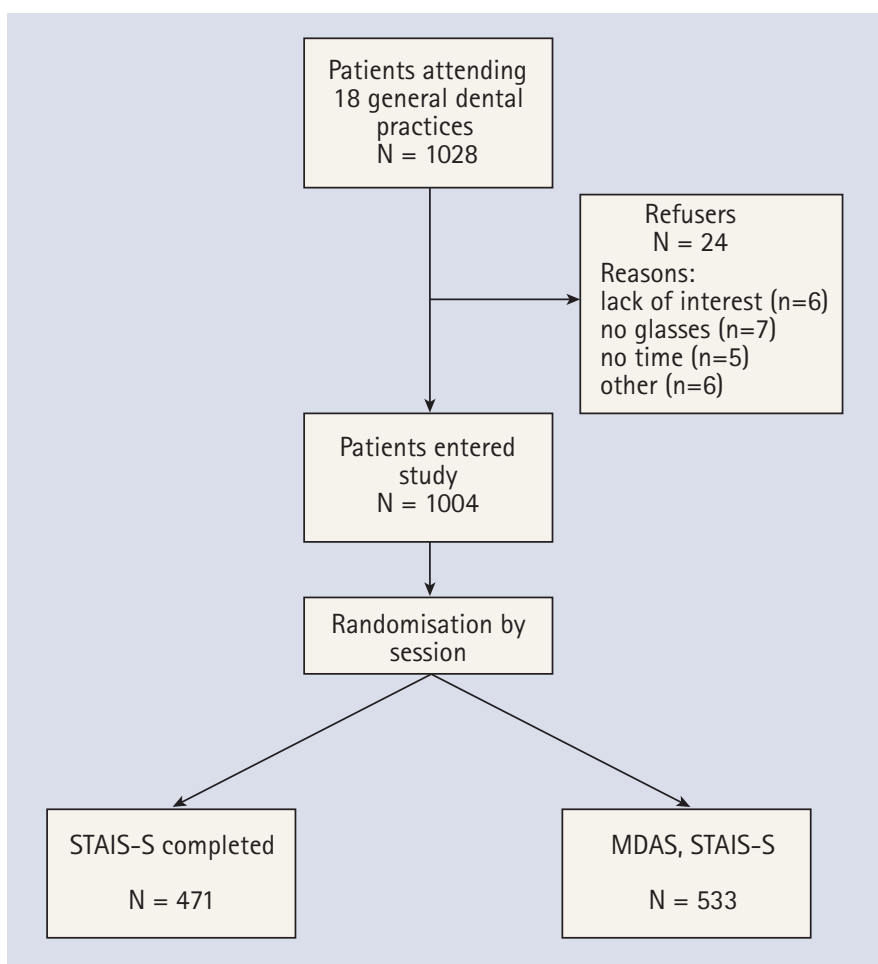

Fig. 1 Trial Profile

assignment between the two groups. The $t$-test was applied to the STAS-S data to determine difference between the two study arms. Two tailed tests and an alpha level of 0.05 were applied throughout.

\section{RESULTS}

Of the 1,028 patients who were approached, 24 refused (Fig. 1 ). Respondents refused due to lack of interest $(n=6)$, non-possession of glasses ( $(n=7)$, insufficient time $(n=5)$, or other miscellaneous reasons $(n=6)$. The response rate was 98\%. Drop-out analysis revealed no difference between respondents and refusers, with the exception that the refusers were older (mean (SD) years: refusers $=$ 52(19) vs respondents $=41(16), t=3.09$, df1, $p=0.002$ ).

Complete data were obtained from 1,004 respondents. Their mean (SD; range) age was 41 (16; 16 to 90) years; 649 (65\%) were female. Sixty-seven percent $(n=673)$ claimed to visit the dentist at least every six months, and 47\% (473) expected to receive a check up rather than dental treatment. The randomisation procedure resulted in approximately the same $(p>0.05)$ demographic profile (age, sex), self-reported regularity of dental attendance and expectations of treatment (Table 1). The mean (SD) level of dental anxiety as reported by the MDAS (internal consistency $=0.90$ for this sample) was 10.7 (4.3), with 6\% scoring 19 or above indicating high dental anxiety. The STAIS-S scores (internal consistency $=0.86$ for this sample) when pro-rated to the Full-form of 20 items gave an overall mean (SD) of 37.3 (14.5).

The mean levels of state anxiety using the raw scores from the six items (ie not pro-rated to the 20 item version) were the same across the two groups $(t=1.28, \mathrm{df}=1002, p=0.2$; Table 2$)$. The mean difference (CI95\%) was 0.35 (0.89 to -0.18). The analysis was repeated with only those patients who claimed to visit the dentist at greater than six month intervals $(\mathrm{n}=331)$. The mean $(\mathrm{SD})$ levels of state anxiety were 12.3 (4.9) and 11.8 (4.8) for the MDAS and non MDAS conditions respectively, confirming a non statistical difference $(t=0.96, \mathrm{df}=329, p=0.3)$

\section{DISCUSSION}

This is the first study that has deliberately tested for the immediate negative effects of asking adult patients about their dental 
Table 1 Age, gender, self-reported regularity of dental attendance and expected treatment across group assignment

\begin{tabular}{lllll}
\hline & $\begin{array}{l}\text { No Dental anxiety } \\
\text { Questionnaire Group }\end{array}$ & \multicolumn{2}{l}{$\begin{array}{l}\text { Dental anxiety } \\
\text { Questionnaire Group }\end{array}$} \\
\hline Age: Mean (SD) & 41.3 & $(15.4)$ & 41.5 & $(16.3)$ \\
& $N$ & $(\%)$ & $N$ & $(\%)$ \\
Gender & 159 & $(34)$ & 196 & $(37)$ \\
\hline Male & 312 & $(66)$ & 337 & $(63)$ \\
Female & & & & \\
$\begin{array}{l}\text { Self-reported regularity } \\
\text { of attendance }\end{array}$ & 312 & $(66)$ & 361 & $(68)$ \\
\hline $\begin{array}{l}\text { Every 6 months or more } \\
\text { Less than every 6 months }\end{array}$ & 159 & $(34)$ & 152 & $(32)$ \\
Expected treatment & & & & \\
\hline $\begin{array}{l}\text { Check up } \\
\text { Treatment }\end{array}$ & 209 & $(44)$ & 262 & $(49)$ \\
\hline
\end{tabular}

Table 2 Situational anxiety (STAIS-S) means, standard deviations and confidence intervals for the two study groups

\begin{tabular}{lllll}
\hline & $\begin{array}{l}\text { No Dental anxiety } \\
\text { Questionnaire Group }\end{array}$ & $\begin{array}{l}\text { Dental anxiety } \\
\text { Questionnaire Group }\end{array}$ & $t$ & $p$ \\
\hline Mean & 11.01 & 11.36 & 1.29 & 0.20 \\
SD & 4.35 & 4.33 & & \\
$(95 \% \mathrm{Cl})$ & $10.62,11.40$ & $10.99,11.73$ & & \\
\hline
\end{tabular}

anxiety at the time when they will be entering the dental surgery for their appointment. This brief study has confirmed that the adoption of a self-reported brief questionnaire to assess dental anxiety immediately prior to entering the dental surgery did not significantly increase the patient's anxiety. When the sample was restricted to those who reported less regular attendance the same result was found. As patients who are irregular attendees report higher levels of dental anxiety, this would suggest that the finding of this study may be robust across a range of dental anxiety levels. The result supports previous work that the introduction of a brief self-report tool to assess dental anxiety has no measurable short term deleterious effects on patients. ${ }^{4,5}$ Previous studies have tended to assess the effect on the patient's post-treatment anxiety or pain perception level. An interesting extension of this work has been the introduction of a dental anxiety questionnaire into the clinical case management of dental patients. ${ }^{15}$ The patient handing to their dentist their completed dental anxiety questionnaire appeared to have a significant benefit on state anxiety levels when leaving the surgery. The study had not however rated the state anxiety prior to entry into the surgery - an omission which this present investigation has addressed.

The level of participation was high in the study although of those who refused there was an over-representation of older people. The study is limited to patients residing in a region of Northern Ireland. Nevertheless, the study sample compared well to other groups, as demonstrated by the mean dental anxiety level (10.7) being comparable to the norm for general practice UK attendees (mean $=10.8){ }^{9}$

Therefore the recommendation of this brief report is that formal assessment of dental anxiety prior to treatment can be used with confidence as an adjunct to the treatment of adult patients attending general practice.

We would like to thank Aoibheann McGahan and Lisa Hall for their assistance with the data collection and data entry. We would also like to acknowledge the dental practitioners and their patients who participated in the study. Work conducted within the geographical boundaries of the SHSSB, Northern Ireland.

1. Kent G. Dental phobias. In Davey G (Ed) Phobias - a handbook of theory, research and treatment London: John Wiley and Sons Ltd, 1997.

2. Newton J, Buck D. Anxiety and pain measures in dentistry: a guide to their quality and application. J Amer Dent Assoc 2000; 131: 1449-1457.

3. Schuurs A, Hoogstraten J. Appraisal of dental anxiety and fear questionnaires: review. Comm Dent Oral Epidemiol 1993; 21: 329-339.

4. Kent G. Effect of pre-appointment inquiries on dental patients' post-appointment ratings of pain. BrJ Med Psych 1986; 59: 97-99.

5. Carlsen $A$, Humphris $G M$, Lee $G T R$, Birch $R H$. The effect of pre-treatment enquiries on child dental patients' post-treatment ratings of pain and anxiety. Psychology and Health 1993; 8: 165-174.

6. Dailey $Y$, Humphris G, Lennon M. The use of dental anxiety questionnaires: a survey of a group of UK dental practitioners. Br Dent J 2001; 190: 450-453.

7. Beatty R. Northern Ireland Multiple Deprivation Measure 2001 - A user's guide NISRA Occasional Paper. Belfast: Northern Ireland Statistics and Research Agency, 2004

8. Corah N L. Development of a dental anxiety scale. J Dent Res 1969; 48: 596.

9. Humphris G M, Morrison T, Lindsay S J E. The Modified Dental Anxiety Scale: UK norms and evidence for validity. Comm Dent Health 1995: 12: 143-150.

10. Humphris G M, Freeman $R_{1}$ Campbell J et al. Further evidence for the reliability and validity of the Modified Dental Anxiety Scale. Int Dent J2000; 50: 376-380.

11. Marteau TM, Bekker $H$. The development of a six-item short-form of the stale of scale of the Spielberger State-Trait Anxiety Inventory (STAI). Br J Clin Psych 1992; 31: 301-306

12. Speilberger C. Manual for the State-Trait Anxiety STAI (Form Y). Palo Alto, CA Consulting Psychologists Press, 1983

13. Barnes $L$, Harp D, Jung W. Reliability generalization of scores on the Speilberger State-Trait Anxiety Inventory. Educ Psych Meas 2002; 62: 603-618.

14. Gardner M, Altman D. Statistics with confidence: confidence intervals and statistical guidelines London: British Medical Journal, 1989.

15. Dailey $Y$, Humphris $G$, Lennon $M$. Reducing patients' state anxiety in general dental practice: a randomized controlled trial. J Dent Res 2002; 81:319-322. 